\title{
Anatomical, physiological, and logistical indications for the open abdomen: a proposal for a new classification system
}

\author{
Joao Rezende-Neto ${ }^{1 *}$, Timothy Rice ${ }^{1}$, Emanuelle Savio Abreu², Ori Rotstein ${ }^{1}$ and Sandro Rizoli ${ }^{1}$
}

\begin{abstract}
Background: A systematic approach to the appropriate use of the open abdomen strategy has not been described. We propose three fundamental reasons for the use of this strategy, anatomical, physiological and logistical. Anatomical reasons pertain to the inability to bring the fascial edges together including soft tissue defects. Physiological reasons relate to features of systemic dysfunction. Logistical reasons involve any anticipated abdominal re-intervention while preserving fascia. These categories occur either as a single reason or in any combination.

Methods: A single-center prospective observational study of patients with open abdomens in trauma and acute abdomen. Surgeons were asked to select from the three reasons (single or any combination of) their motivation for using the open abdomen upon completion of the initial operation. Patients were compared using the non-parametric Wilcoxon two-sample test or Kruskal-Wallis test. Chi-square or Fisher's exact test was used for categorical variables; Statistical significance set at $P$-value $\leq 0.05$.

Results: Forty-five consecutive patients with open abdomens were evaluated (Jan. 1- Dec. 31, 2012). Mean age was 38.8 years, 32 were male, 39 (86.7 \%) sustained trauma. The most common single reason for the open abdomen was physiological (24.4\%), 33 patients had multiple reasons, the most common combination being anatomical and physiological (22.2\%). A physiological reason was linked to: lower $\mathrm{pH}$, higher lactate, and lower systolic blood pressure on admission $(p<0.05)$. A logistical reason was associated with earlier primary fascial closure, intra-operative packing, and bowel left in discontinuity. Logistic regression and adjusted odds ratio of primary fascial closure was: physiological $(0.08,95 \% \mathrm{Cl}, 0.01-0.92, p=0.043)$; logistical $(6.03,95 \% \mathrm{Cl}, 1.13-32.29, p=0.036)$; and anatomical $(0.83,95 \% \mathrm{Cl}, 0.16-4$. $18, p=0.816)$.
\end{abstract}

Conclusion: We defined three basic indications for the use of the open abdomen, anatomical physiological and logistical. These indications establish a practical and comprehensive terminology that could help to promote appropriate use of the open abdomen.

Keywords: Open abdomen, Trauma, Acute care surgery, Classification

\footnotetext{
* Correspondence: rezendenetoj@smh.ca

'Department of Surgery Division of General Surgery, University of Toronto, St.

Michael's Hospital, 30 Bond Street, Rm 3-074 Donnelly Wing, Toronto, ON

M5B 1 W8, Canada

Full list of author information is available at the end of the article
} 


\section{Background}

The open abdomen is considered a hallmark of damage control surgery. With the widespread use of this stagedapproach to the laparotomy, the open abdomen has become an acceptable option in the operative management of critically ill patients [1,2]. Despite the use of the open abdomen technique by trauma and acute care surgeons, the fundamental indications that define its appropriate application are poorly understood [3-5]. The need to establish consensus indications was made clear by a recent meta-analysis reporting over one thousand indications for damage control surgery found throughout the literature [6]. The indications for the open abdomen and damage control surgery are often applied interchangeably. In many instances however, the open abdomen strategy can be used outside the context of the physiologic abnormalities associated with damage control surgery. Thus, the current indications for damage control surgery may not be sufficiently broad to guide the use of the open abdomen $[3,7]$. Consequently, a comprehensive definition of the indications for the appropriate use of the open abdomen is required [8].

The purpose of this study was to introduce a classification system supported by clinical data that provides practical and comprehensive terminology of the indications for the open abdomen.

\section{Methods}

The Research Ethics Committee of the Risoleta Tolentino Neves Hospital approved the conduct of this study (resolution number 196/96/23/2/07), informed consent was waived. This was a single-center prospective observational study.

Patients were screened on weekdays between 7:0019:00 h at the Hospital Universitario Risoleta Tolentino Neves, a regional trauma center affiliated with the Federal University of Minas Gerais, located in Belo Horizonte, Brazil. This time interval relates to availability of research assistants at the institution. Patients admitted to the trauma acute care surgery service that required a laparotomy for trauma or an acute abdomen where an open abdomen strategy was used fulfilled the study inclusion criteria. Patients were excluded if they were less than 18 years of age.

Research assistants approached the primary surgeon in the operating room after the decision to use an open abdomen technique was already made. The acute care surgery/trauma call schedule of the institution has a different team of surgeons on call each day of the week working on $12 \mathrm{~h}$ shifts. All surgeons who performed the operations were experienced general surgeons with subspecialization in trauma and acute care surgery. These surgeons were given a questionnaire that described the nature of the study and were asked to select one or more reasons for why they decided to leave the abdomen open.
Management of the patients remained entirely at the discretion of the surgeons.

We defined three basic indications for the use of the open abdomen, anatomical physiological and logistical:

- Anatomical indications are represented by the inability to approximate the edges of the laparotomy and perform primary closure, soft tissue loss, or impending risk of abdominal compartment syndrome.

- Physiological indications pertain to a severe physiologic derangement of the patient requiring damage-control damage control strategies.

- Logistical indications occur when serial surgical interventions are necessary while preserving fascia.

Surgeons were also allowed not to choose any of the aforementioned indications and/or add additional reasons for the open abdomen. All questionnaires were completed before the surgeon left the operating room and were given directly back to the research coordinator. Research personnel assessed patients daily for clinical outcomes. Patients were followed until the time of hospital discharge or when censored at 7 days.

\section{Statistical analysis}

Descriptive statistics were calculated as means, standard deviations, medians, interquartile ranges, and proportions. Patient groups were compared using the non-parametric Wilcoxon two-sample test or Kruskal-Wallis test for age, hospital length of stay, Intensive care Unit (ICU) length of stay, and Injury Severity Score (ISS). Chi-square or Fisher's exact test was used for categorical variables. The association between all three reasons for abdominal closure failure and death was estimated from a logistic regression model (odds ratios and $95 \%$ confidence intervals). All analyses were performed using SAS 9.4 (SAS Institute, Inc., Cary, NC) and SPSS Statistics 22 (IBM, Inc.). Statistical significance was set at a two-sided $P$-value of 0.05 or less.

\section{Results}

A total of 24,218 patients were assessed by the trauma acute care surgery service from January 1, 2012 to December 31, 2012. This included patients presenting with all types of surgical pathologies and traumas of all magnitudes, including minor injuries. Of these, 821 patients required a laparotomy and 313 were screened for eligibility. Another 508 patients also had a laparotomy but were not screened because the operations were not performed during the study hours; 64 of those patients had an open abdomen (12.6\%). Enrollment is outlined in the CONSORT diagram in Fig. 1.

Forty-five patients had an open abdomen following a laparotomy for either trauma or acute abdomen, on 


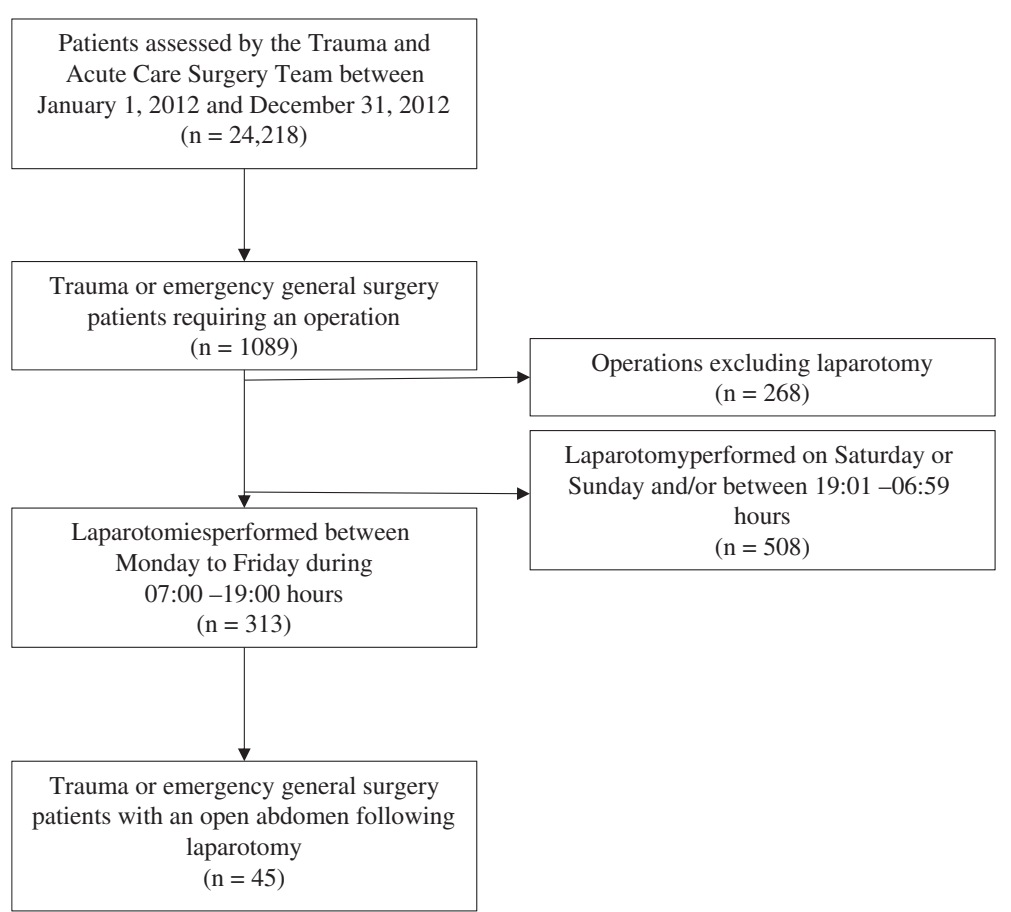

Fig. 1 Consort flow chart describing patients enrolled in the study. Patients assessed by the trauma and acute care surgery team include all patients that required emergency surgical consultation and traumas of all severities

weekdays between 7:00 and 19:00 h, and were enrolled in the study.

The baseline characteristics of the cohort according to each of the three reasons are presented in Table 1.

The mean age was $38.8 \pm 18.8$ years old and $32(71.1 \%)$ patients were male. Thirty-nine $(86.7 \%)$ patients required a laparotomy for trauma. The mean Injury Severity Score was 22.2 (interquartile range, 16-34). Temporary abdominal closure was performed using a Bogota bag in 40 (88.9\%) patients and negative pressure wound therapy in 3 (6.7 \%) patients. Both temporary abdominal closure techniques were used in $2(4.4 \%)$ patients.

Patients with physiological reasons compared to those without physiological reasons had a significantly higher lactate (lactate $>5.0 \mathrm{mmol} / \mathrm{L}: 63.2 \%$ vs. $14.3 \% ; p=0.034$ ); lower $\mathrm{pH}(\mathrm{pH}<7.2: 71.1 \%$ vs. $0 \%$; $p<0.001)$ and lower systolic blood pressure (SBP $<90 \mathrm{mmHg}$ : $92.1 \%$ vs. $57.1 \% ; p=0.039)$ on admission.

Fifteen (33.3\%) patients had a single reason for leaving the abdomen open. The most common single reason for the open abdomen was physiologic $(n=11,24.4 \%)$. Of the 30 patients with multiple reasons, $27(90 \%)$ had a physiologic reason. Physiologic and anatomic reasons were the most frequently identified combinations $(n=10,22.2 \%)$.

Primary fascial closure was obtained in 19 (42.2 \%) patients (Table 2).

Eleven patients (58 \%) had primary fascial closure within 72-h. Rates of primary fascial closure within 72-h was highest among those with logistical reasons (38.1\%) compared to $12.5 \%$ if a logistical reason was absent $(p=0.048)$. Patients with physiological reasons were less likely to have primary fascial closure compared to those without physiological reasons $(34.2 \%$ vs. $85.7 \%$, OR, 0.09; $95 \% \mathrm{CI}, 0.01-0.80 ; p=0.031$ ). Patients with logistical reasons were more likely to have primary fascial closure during hospital stay than those without logistical reasons $(61.9 \%$ vs. $25.0 \%$, OR, 4.88; $95 \%$ CI, $1.36-17.47 ; p=0.012)$. There was no significant association between primary fascial closure among patients with anatomical reasons or among those with multiple reasons compared to single reasons $(p=0.787$ and $p=0.393$, respectively).

Because a physiological reason was highly prevalent, we also performed a logistic regression analysis to examine the joint association of all three reasons with successful primary fascial closure. In logistic regression, the adjusted odds ratio (AOR) of primary fascial closure was as follows: physiological $(0.08,95 \% \mathrm{CI}, 0.01-0.92 ; p=0.043)$; logistical (6.03, $95 \%$ CI, 1.13-32.29; $p=0.036)$; and anatomical (0.83, $95 \%$ CI, 0.16-4.18; $p=0.816$ ) (Table 3).

Intraoperatively, patients with logistical reasons had significantly higher rates of packing than when that reason was not present $(42.9 \%$ vs. $0 \% p<0.001)$. Bowel resections and bowel left in discontinuity were also more common in patients with logistical reasons; respectively $(57.1 \%$ vs. $12.5 \% ; p=0.004$ and $42.9 \%$ vs. $0 \%$; $p<0.001$ ) (Table 4 ). 
Table 1 Baseline characteristics and laboratory values among physiological, anatomical, and logistical reasons in patients with open abdomens

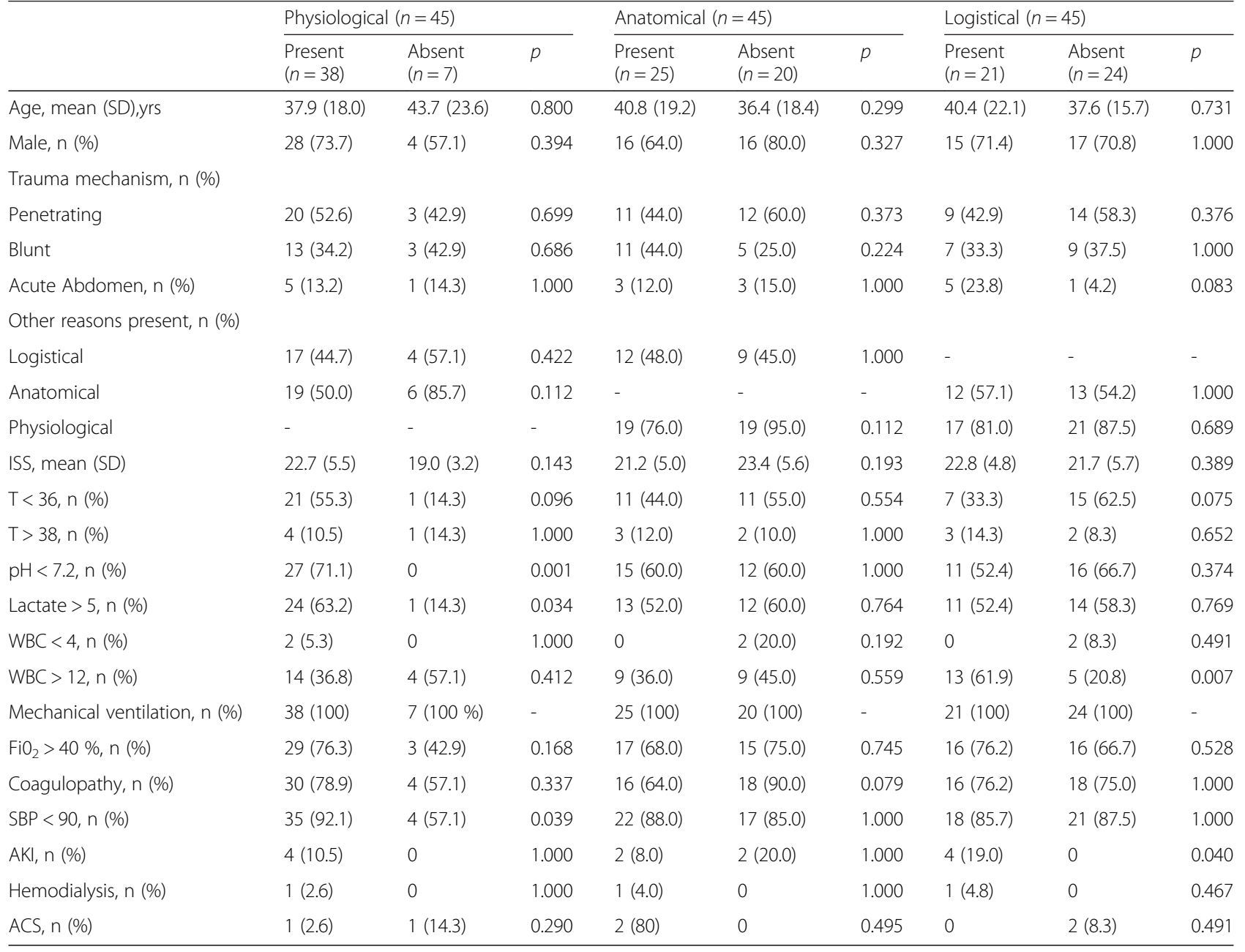

$S D$ standard deviation, ISS injury severity score, $T$ temperature, $W B C$ white blood cell count, $\mathrm{FiO}_{2}$ fraction of inspired oxygen, $S B P$ systolic blood pressure, $A K I$ acute kidney injury, ACS abdominal compartment syndrome

The overall mortality rate was $44.4 \%$. Of the 20 patients that died, 14 (70 \%) died within the first 24-h. Mortality was most common in patients with physiological reasons ( $n=19,50.0 \%$ ); however, none of the reasons were significantly associated with mortality. Bleeding was the most common cause of death for all reasons. Multi-organ failure as a cause of death was lower in patients with anatomical (anatomical $12.0 \%$ vs. without anatomical $40 \% ; p=0.041$ ) and logistical reasons (logistical $9.5 \%$ vs. $37.5 \%$ without logistical reason; $p=0.040$ ).

\section{Discussion}

The open abdomen strategy is commonly used in modern surgical practice. With greater understanding of damage control principles it has become widely adopted by trauma and acute care surgeons [1]. Our knowledge of the open abdomen has, however, trailed behind our enthusiasm, as the indications guiding its appropriate use remain undefined.
Furthermore, despite employing techniques previously described to repair incisional ventral hernias and the significant improvement in mesh construction early closure of the open abdomen remains a challenge $[9,10]$. The average rate of primary fascial closure was $62 \%$ in a recent systematic review and meta-analysis involving more than 3000 patients with open abdomens [11]. It was demonstrated in that study, after adjusting for patient heterogeneity, that primary fascial closure had a significant role in mortality reduction, decreasing complications and hospital length of stay [11]. These findings highlight the importance of judicious use of the open abdomen strategy.

Progress towards better defining its indications has been hampered by the lack of a common language and the absence of the widespread adoption of an open abdomen classification system. With the introduction of consensus definitions and a new system of standardized nomenclature, there has been some headway with the former but a 
Table 2 Outcomes among physiological, anatomical, and logistical reasons in patients with open abdomens

\begin{tabular}{|c|c|c|c|c|c|c|c|c|c|}
\hline & \multicolumn{3}{|c|}{ Physiological $(n=45)$} & \multicolumn{3}{|c|}{ Anatomical $(n=45)$} & \multicolumn{3}{|c|}{ Logistical $(n=45)$} \\
\hline & $\begin{array}{l}\text { Present } \\
(n=38)\end{array}$ & $\begin{array}{l}\text { Absent } \\
(n=7)\end{array}$ & $p$ & $\begin{array}{l}\text { Present } \\
(n=25)\end{array}$ & $\begin{array}{l}\text { Absent } \\
(n=20)\end{array}$ & $p$ & $\begin{array}{l}\text { Present } \\
(n=21)\end{array}$ & $\begin{array}{l}\text { Absent } \\
(n=24)\end{array}$ & $p$ \\
\hline ICU LOS (IQR) & $5(1-5)$ & $15(12-21)$ & 0.230 & $12(1-27.5)$ & $4.5(1-11.8)$ & 0.399 & $10(1.5-24)$ & $4.5(1-27.8)$ & 0.541 \\
\hline Hospital LOS (IQR) & $7(1-7)$ & $33(22-43)$ & 0.133 & $27.8(1-41)$ & $7(1-21.5)$ & 0.495 & $19(2.5-42.5)$ & $5(1-34.5)$ & 0.300 \\
\hline Primary fascial cl, n (\%) & $13(34.2)$ & $6(85.7)$ & 0.031 & $11(44.0)$ & $8(40.0)$ & 1.000 & $13(61.9)$ & $6(25.0)$ & 0.017 \\
\hline $0-24 \mathrm{~h}$ & $2(5.3)$ & $1(14.3)$ & 0.405 & 0 & $3(15.0)$ & 0.080 & $3(14.3)$ & 0 & 0.094 \\
\hline $24-48 \mathrm{~h}$ & $1(2.6)$ & $3(42.9)$ & 0.009 & $3(12.0)$ & $1(5.0)$ & 0.617 & $2(9.5)$ & $2(8.3)$ & 1.000 \\
\hline $48-72 \mathrm{~h}$ & $3(7.9)$ & $1(14.3)$ & 0.505 & $2(8.0)$ & $2(10.0)$ & 1.000 & $3(14.3)$ & $1(4.2)$ & 0.326 \\
\hline $72-96 \mathrm{~h}$ & $2(5.3)$ & 0 & 1.000 & $2(8.0)$ & 0 & 0.495 & $1(4.8)$ & $1(4.2)$ & 1.000 \\
\hline $96-120 \mathrm{~h}$ & $1(2.6)$ & $1(14.3)$ & 0.290 & $2(8.0)$ & 0 & 0.495 & $2(9.5)$ & 0 & 0.212 \\
\hline $120-144 \mathrm{~h}$ & $1(2.6)$ & 0 & 1.000 & $1(4.0)$ & 0 & 1.000 & $1(4.8)$ & 0 & 0.467 \\
\hline $144-168$ h & $3(7.9)$ & 0 & 1.000 & $1(4.0)$ & $2(10.0)$ & 0.577 & $1(4.8)$ & $2(8.3)$ & 1.000 \\
\hline Fascial $\mathrm{cl} \leq 72 \mathrm{~h}, \mathrm{n}(\%)^{\mathrm{a}}$ & $6(15.8)$ & $5(71.4)$ & 0.004 & $5(20.0)$ & $6(30.0)$ & 0.500 & $8(38.1)$ & $3(12.5)$ & 0.048 \\
\hline Mortality, n (\%) & $19(50.0)$ & $1(14.3)$ & 0.112 & $10(40.0)$ & $10(50.0)$ & 0.557 & $7(33.3)$ & $13(54.2)$ & 0.231 \\
\hline $0-24 \mathrm{~h}$ & $13(34.2)$ & $1(14.3)$ & 0.407 & $8(32.0)$ & $6(30.0)$ & 1.000 & $5(23.8)$ & $9(37.5)$ & 0.356 \\
\hline $24-48 \mathrm{~h}$ & $1(2.6)$ & 0 & 1.000 & 0 & $1(5.0)$ & 0.444 & 0 & $1(4.2)$ & 1.000 \\
\hline $48-72 \mathrm{~h}$ & $2(5.3)$ & 0 & 1.000 & 0 & $2(10.0)$ & 0.192 & 0 & $2(8.3)$ & 0.491 \\
\hline $72-96 \mathrm{~h}$ & $2(5.3)$ & 0 & 1.000 & $1(4.0)$ & $1(5.0)$ & 1.000 & $1(4.8)$ & $1(4.2)$ & 1.000 \\
\hline $96-120 \mathrm{~h}$ & $1(2.6)$ & 0 & 1.000 & $1(4.0)$ & 0 & 1.000 & $1(4.8)$ & 0 & 0.467 \\
\hline $120-144 \mathrm{~h}$ & 0 & 0 & - & 0 & 0 & - & 0 & 0 & - \\
\hline $144-168 \mathrm{~h}$ & 0 & 0 & - & 0 & 0 & - & 0 & 0 & - \\
\hline \multicolumn{10}{|l|}{ Cause of death, n (\%) } \\
\hline Sepsis & $4(10.5)$ & $1(14.3)$ & 1.000 & $3(12.0)$ & $2(10.0)$ & 1.000 & $2(9.5)$ & $3(12.5)$ & 1.000 \\
\hline MOF & $10(26.3)$ & $1(14.3)$ & 0.663 & $3(12.0)$ & $8(40.0)$ & 0.041 & $2(9.5)$ & $9(37.5)$ & 0.040 \\
\hline Bleeding & 12 (31.6) & $1(14.3)$ & 0.654 & $9(36.0)$ & $4(20.0)$ & 0.327 & $6(28.6)$ & $7(29.2)$ & 1.000 \\
\hline
\end{tabular}

ICU intensive care unit, LOS length of stay, IQR interquartile range, $\mathrm{Cl}$ closure, MOF multi-organ failure

${ }^{a}$ statistically significant difference compared to fascia closed $>72 \mathrm{~h}$ and fascia not closed

robust classification system is still missing [5, 12]. Additionally, diverse practice patterns between studies and the inclusion of heterogeneous population of patients have contributed to the paucity of evidence-based data [3, 6]. The need for higher quality data in all facets of the management of the open abdomen has been the impetus for the development of an International Register of Open Abdomen promoted by the World Society of Emergency Surgery

Table 3 Logistic regression model results of variables related to primary fascial closure

\begin{tabular}{llll}
\hline Factors & OR & $95 \%$ Wald confidence intervals & $p$ \\
\hline Age & 1.06 & $0.99-1.13$ & 0.1050 \\
Logistical & 6.03 & $1.13-32.29$ & 0.0358 \\
Anatomical & 0.83 & $0.16-4.18$ & 0.8158 \\
Physiological & 0.08 & $0.01-0.92$ & 0.0425 \\
Blunt mechanism & 0.20 & $0.02-1.75$ & 0.1476 \\
Acute Abdomen & 0.43 & $0.01-16.14$ & 0.6456 \\
\hline
\end{tabular}

OR odds ratio
[3]. Nevertheless, no level one recommendations can be made with respect to the indications for the open abdomen in damage control or emergency general surgery $[3,7]$.

The classification presented herein, defines three categories that encompass all of the indications for the open abdomen: anatomical; physiological; and logistical. We believe that this classification has practical application and effectively homogenizes patients based on clinical features and outcomes. Furthermore, it is applicable to both trauma and non-trauma populations, and introduces a simple standardized nomenclature that will facilitate communication and future studies. Moreover, our classification in no way negates previously defined indications for the open abdomen in damage control surgery [13-18].

Damage control surgery laid the foundation for our understanding of the open abdomen and, as a result, the use of the open abdomen in modern surgical practice has largely been extrapolated from the damage control surgery literature. Hence, it is not surprising that the most common category used to define the indications for the open 
Table 4 Temporary abdominal closure strategy and operative interventions among physiological, anatomical, and logistical reasons in patients with open abdomens

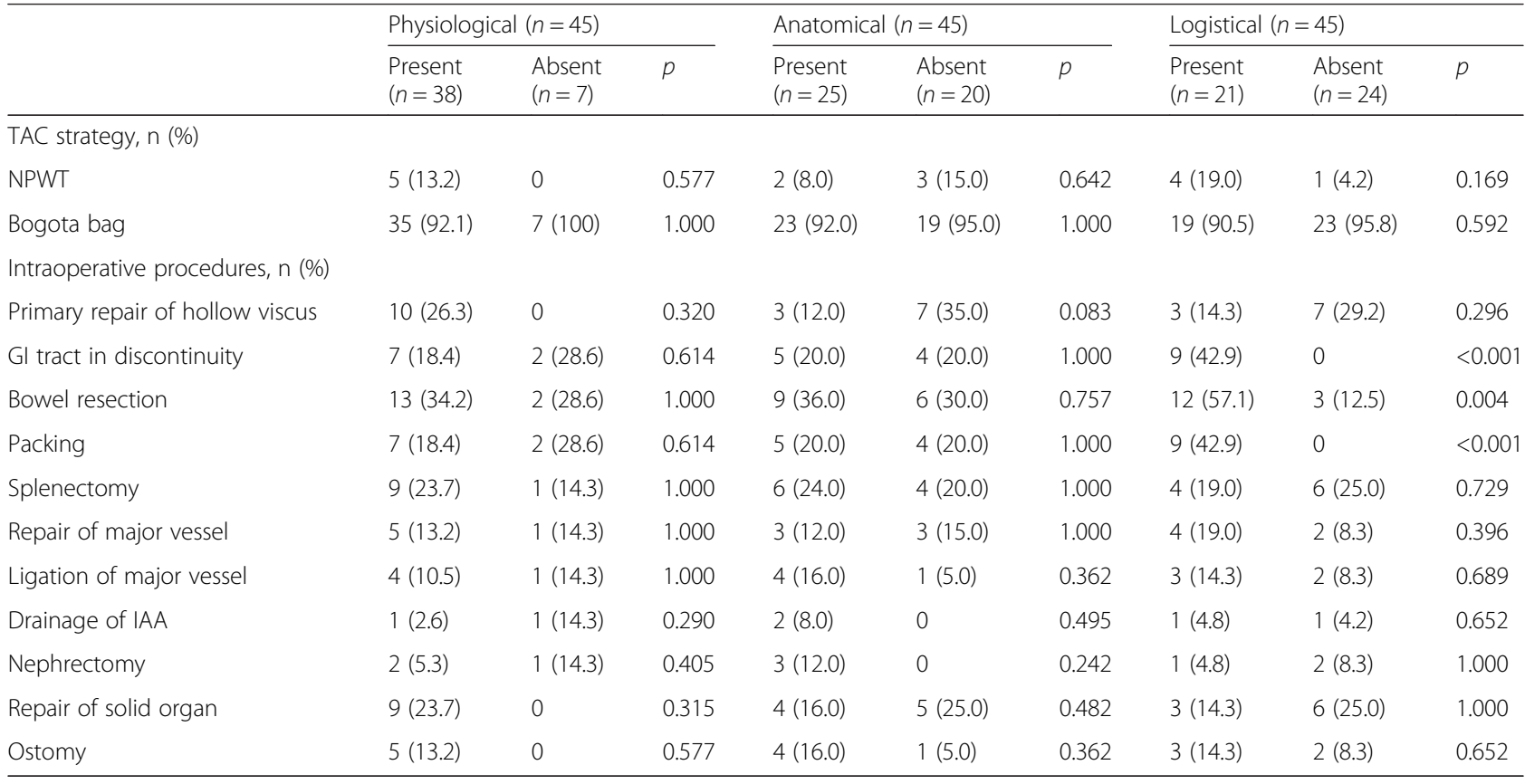

TAC temporary abdominal closure, NPWT negative pressure wound therapy, G/ gastrointestinal tract, IAA intra-abdominal abscess

abdomen is based on patient's physiologic parameters $[13,19]$. This current framework is overly restrictive and neglects other important considerations relevant to the open abdomen. Dichotomizing the open abdomen and damage control surgery is important to successfully define its appropriate use.

A classification system derived from local findings specific to the open abdomen was originally proposed by Bjork et al $[5,20]$. This classification describes four categories that are based on the degree of adhesions and degree of enteric contamination. One of the strengths of this classification lies in its ability to describe the natural history and grade the progressively increasing complexity of the open abdomen management [21]. Included in the most complex category are, enteric leak, deteriorating grade, and the presence of an enteroatmospheric fistula. All have been shown to reliably predict a worse clinical outcome [20,21]. This classification, however, has limited usefulness in its ability to establish the initial indications for leaving the abdomen open [22]. Arguably, knowledge of the initial indication should be an integral component of a classification system and is a requisite for facilitating communication between clinicians and investigators. Moreover, since the determinants of the aforementioned classification are predominantly anatomically based it is not sufficiently broad to encompass all of the potential contexts where an open abdomen strategy may be applied.

Since surgeons in our study reported their reasons for leaving the abdomen open immediately after the conclusion of the operation, our findings provide an accurate representation of current surgical practice and offer insight into surgeons' motives for using this surgical strategy. Physiological reasons were the most prevalent indication for the open abdomen in our study. This finding is consistent with a survey of American Association for the Surgery of Trauma members in which respondents reported, "damage control surgery" (a surrogate for physiological derangements) as the most common reason for leaving the abdomen open. This was followed by anatomical reasons: "abdominal organ distention" and "inability to close fascia"; and then logistical reasons: "preparation for a 2nd look" [1]. We also observed a similar distribution in the frequency in our study with anatomical reasons being more common than logistical. However, our findings are at variance with the results of a 2004 survey of Canadian Trauma Surgeons, in which $87 \%$ of respondents reported an anatomical reason, "unbridgeable gap", followed by a logistical reason, "planned re-operation", as being the two most frequently reported indications for the open abdomen [2]. The findings of this survey may simply reflect the evolution of our understanding of the open abdomen over a 10year period but may also reveal the significant variability in practice patterns that exist [23].

In our study, patients with physiological reasons for the open abdomen were also less likely to have primary fascial closure compared to those without physiological reasons. The higher admission lactate level, lower $\mathrm{pH}$, and lower systolic blood pressure in those with physiological reasons lends further support to the association between the severity of physiologic derangement and the subsequent inability 
to obtain primary fascial closure. This link was reported in a prospective multi-institutional study that identified risk factors for failure to achieve primary fascial closure among trauma patients with an open abdomen [24]. The authors similarly found that patients who did not have primary fascial closure were more likely to have a lower admission $\mathrm{pH}$ and a lactate $\geq 7.5$ [24]. Interestingly, the presence of an additional reason (anatomical and/or logistical) to a physiological reason did not confer an increased risk of failure to obtain primary fascial closure in our series. The eleven patients who had isolated physiological reason may therefore represent a cohort of patients at greatest risk for failed fascial closure. This was contrary to our intuitive assumptions that the presence of multiple indications would increase the risk of failure of primary fascial closure. This should be explored further.

We found that patients with a logistical reason were most likely to have primary fascial closure compared to those without a logistical reason. Logistical determinants are frequently based upon a deliberate decision to return to the operating room rather than the status of the abdominal wall or the patient's clinical condition. In logistical reasons, fascial closure is usually possible and would be physiologically tolerated but the decision is made not to close the abdomen. Several studies have demonstrated that patients who require fewer re-laparotomies, and who have shorter duration of open abdomen management have higher rates of primary fascial closure $[25,26]$. Earlier closure has also been associated with improved post-operative outcomes [27]. In our series, logistical reasons, as expected, were associated with significantly higher rates of the bowel left in discontinuity and packing compared to the absence of that reason. In both of these clinical scenarios, a high rate of successful primary fascial closure would be expected at the first re-laparotomy [25]. The greater potential for obtaining early primary fascial closure is a defining characteristic of patients with logistical reasons and likely contributes to the high rate of fascial closure observed in this cohort.

Recently, Chiara et al. led an expert panel on open abdomens in trauma and published consensus recommendations defining the indications for its appropriate use [28]. The authors recommend the use of the open abdomen technique in several clinical scenarios, all of which can be organized into anatomical, logistical, and/or physiological categories described in our classification system. In that study, extreme visceral edema, retroperitoneal swelling, and elevated bladder pressure when closing harmonize with anatomical reasons for the open abdomen described herein. Logistical reasons include planned re-laparotomy for vascular/gastrointestinal injuries or mesenteric ischemia, packing, hematoma requiring a second look, and peritoneal contamination that has not resolved at the conclusion of the first operation [27]. Physiological reasons include, critically ill patients requiring abbreviated "damage control" procedures
[28]. Similarly, the Eastern Association for the Surgery of Trauma Practice Management Guidelines recommends the use of the open abdomen in the context of severe abdominal trauma with intra-abdominal packing, acidosis, hypothermia, clinical coagulopathy, and massive transfusion [4]. Moreover, severe necrotizing pancreatitis and severe intrabdominal infection/peritonitis are part of the indications for the open abdomen in emergency general surgery [4]. Essentially, the three categories described in our study act as umbrella terms that encompass a broad range of clinical scenarios that could guide decisionmaking when considering the use of the open abdomen strategy. Therefore, we suggest that perhaps one should ask if there are any anatomical, logistical and or physiological reasons to leave the abdomen open before opting for this strategy. We consider that if none of these reasons are present the abdomen should be closed.

While the use of the open abdomen in trauma is widely endorsed by important guidelines, its use in the non-trauma setting is often contradictory [25]. In a recent meta-analysis of the open abdomen in non-trauma patients the most frequent indication was a planned re-laparotomy (or logistical according to our classification) [25]. This is in contrast to a retrospective review on damage control surgery in nontrauma patients where physiological reasons were more frequently described for leaving the abdomen open [27]. Moreover, practice patterns differ considerably in the nontrauma setting with some endorsing the use of the open abdomen only when the abdominal cavity cannot be physically closed [25]. The majority of our non-trauma patients had multiple indications for the open abdomen with both physiological and logistical reasons being present in all but one patient. Thus, our classification is conceptually useful for organizing the indications of the open abdomen in both the trauma and the non-trauma settings.

There are important limitations to our study. The majority of patients in our cohort had multiple reasons for undergoing an open abdomen procedure. This frequently resulted in the same patient being analyzed in more than one group. This potentially limits our ability to attribute with certainty specific clinical characteristics and outcomes to a single reason. In retrospect, it would have been ideal to have the surgeons in our study indicate their primary reason for using the open abdomen followed by their secondary and tertiary reasons when present. Analyzing patients into seven groups that would encompass all of the possible combinations of the three reasons would allow for more specific comparisons. Due to the relatively small sample size in each of these seven groups we were unable to obtain any meaningful analysis with such an approach in the present study. Since the primary intent of this study was to introduce a new classification system, patients were censored early during their hospital course limiting conclusions with respect to complications and long-term follow-up. The consequences 
of the limited use of negative pressure wound therapy in our cohort also apply to that limitation. We also observed a high mortality rate in our study interfering with a comprehensive analysis of the primary fascial closure rate in each category. Lastly, this study was conducted at a single-center with recruitment being limited to daytime hours; a multi-center trial with the potential for 24-h recruitment would improve patient accrual and provide means to further investigate the applicability of our classification.

\section{Conclusions}

The classification, presented herein, proposes that all the indications for the open abdomen can be organized into three categories: anatomical; physiological; and logistical. These categories establish a practical and comprehensive terminology that could help to promote appropriate use of the open abdomen. Our findings suggest that there are significant differences among each of these categories with respect to clinical characteristics and primary fascial closure rates. Efforts are currently underway to conduct a large multi-center prospective observational study to validate this proposal.

\section{Abbreviations}

ICU, intensive care unit; ISS, injury severity score; SBP, Systolic Blood Pressure; $\mathrm{OR}$, odds ratio; $\mathrm{Cl}$, confidence interval

\section{Acknowledgments}

The authors would like to acknowledge the assistance of Rosane Nisenbaum $\mathrm{PhD}$, Associate Scientist, Statistician at the Li Ka Shing Knowledge Institute for her contribution with the statistical analysis of our work.

\section{Funding}

There were no sources of funding for this study.

\section{Availability of data and materials}

Database and all relevant raw data of this study are presented in an additional supporting file without breaching participants' confidentiality.

\section{Authors' contribution}

Literature search: JBRN, TR, ESA; Study Design: JBRN, ESA; Data Collection: JBRN, ESA; Data Analysis: JBRN, TR, SR, OR; Data Interpretation: JBRN, TR, SR, OR; Writing: JBRN, TR, SR, OR Critical review: JBRN, TR, SR, OR. All authors read and approved the final manuscript.

\section{Competing interests}

The authors declare that they have no competing interests.

\section{Consent for publication}

"Not Applicable".

\section{Ethics approval and consent to participate}

The Research Ethics Committee of the Risoleta Tolentino Neves Hospital approved the conduct of this study (resolution number 196/96/23/2/07), informed consent was waived.

\section{Author details}

'Department of Surgery Division of General Surgery, University of Toronto, St. Michael's Hospital, 30 Bond Street, Rm 3-074 Donnelly Wing, Toronto, ON M5B 1 W8, Canada. ${ }^{2}$ Hospital Risoleta Tolentino Neves, Federal University of Minas Gerais, Minas Gerais, Brazil.

Received: 14 March 2016 Revised: 10 May 2016 Accepted: 9 June 2016 Published online: 14 June 2016

\section{References}

1. MacLean A, O'Keefe T, Augenstein J. Management strategies for the open abdomen: Survey of the American Association for the surgery of trauma membership. Acta Chir Belg. 2008;108(2):212-8.

2. Kirkpatrick AW, Laulpand KB, Karmali S, Bergeron E, Stewart C, Findlay C, Parry N, Khetarpal S, Evans D. Spill your guts! Perceptions of trauma association of canada member surgeons regarding the open abdomen and the abdominal compartment syndrome. J Trauma. 2006;60(2):279-86.

3. Coccolini F, Catena F, Montori G, Ceresoli M, Manfredi R, Nita GE, Moore EE, Biffl W, Ivatury R, Whelan J, Fraga G, Leppaniemi A, Sartelli M, Di Silverio S, Ansaloni L. IROA: the International Register of Open Abdomen.: An international effort to better understand the open abdomen: call for participants. World J Emerg Surg. 2015;10:37. doi: 10.1186/s13017-015-0029-

4. Diaz Jr JJ, Cullinane DC, Dutton WD, Jerome R, Bagdonas R, Bilaniuk JW, Collier BR, Como JJ, Cumming J, Griffen M, Gunter OL, Kirby J, Lottenburg L, Mowery N, Riodarn WP Jr, Martin N, Platz J, Stassen N, Winston ES. The management of the open abdomen in trauma and emergency general surgery: part 1-damage control. J Trauma. 2010;68(6):1425-38.

5. Kirkpatrick AW, Roberts DJ, De Waele J, Jaeschke R, Malbrain ML, De Keulenaer B, Duchesne J, Bjorck M, Leppaniemi A, Ejjke JC, Sugrue M, Cheatham M, Ivatury R, Ball CG, Reintam Blaser A, Regli A, Balogh ZJ, D'Amours S, Debergh D, Kaplan M, Kimball E, Olvera C. Pediatric Guidelines Sub-Committee of the World Society of the Abdominal Compartment Syndrome. Intra-abdominal hypertension and the abdominal compartment syndrome: updated consensus definitions and clinical practice guidelines from the World Society of the Abdominal Compartment Syndrome. Intensive Care Med. 2013;39(7):1190-206.

6. Roberts DJ, Bobrovitz N, Zygun DA, Ball CG, Kirkpatrick AW, Faris PD, Stelfox HD. Indications for use of damage control surgery and damage control interventions in civilian trauma patients: A scoping review. J Trauma Acute Care Surg. 2015;78(6):1187-96.

7. Coccolini F, Biffl W, Catena F, Ceresoli M, Chiara O, Cimbanassi S, Fattori L, Leppaniemi A, Manfredi R, Montori G, Pesenti G, Sugrue M, Ansaloni L. The open abdomen, indications, management and definitive closure. World J Emerg Surg. 2015;10:32. doi:10.1186/s13017-015-0026-5.

8. Rezende-Neto JB, Rizoli S, Abreu E, Rotstein O. Three indications for the "open abdomen", anatomical, logistical and physiological: how are they different? Can J Surg. 2015;58 Suppl 1:S40.

9. Rezende-Neto JB, Angarita FA, Rizoli SB, Rotstein OD. Modified triple-layer peritoneal-aponeurotic transposition: A new strategy to close the "open abdomen". J Trauma Acute Care Surg. 2015;79(4):694-7.

10. Chen Y, Ye J, Song W, Chen J, Yuan Y, Ren J. Comparison of outcomes between early fascial closure and delayed abdominal closure in patients with open abdomen: A systematic review and meta-analysis. Gastroenterol Res Pract. 2014:2014:784056. doi:10.1155/2014/784056.

11. Pauli EM, Rosen MJ. Open ventral hernia repair with component separation. Surg Clin N Am. 2013;93(5):1111-33.

12. Sharrock AE, Barker T, Yuen HM, Rickard R, Tai N. Management and closure of the open abdomen after damage control laparotomy for trauma. A systematic review and meta-analysis. Injury. 2015. Advanced on line publication. doi: 10.1016/.jinjury.2015.09.008.

13. Morris JA, Eddy VA, Rutherford EJ. The trauma celiotomy: The evolving concepts of damage control. Curr Probl Surg. 1996;33(8):611-700.

14. Asensio JA, McDuffie L, Petrone P, Roldan G, Forno W, Gambaro E, Salim A, Demetriades D, Murray J, Velmahos $G$, et al. Reliable variables in the exsanguinated patient which indicate damage control and predict outcome. Am J Surg. 2001;182:743-51.

15. Garrison JR, Richardson JD, Hilakos AS, Sapin DA, Wilson MA, Miller FB, Fulton RL. Predicting the need to pack for severe intra-abdominal hemorrhage. J Trauma. 1996;40:923-7. discussion 927-929.

16. Offner PJ, De Souza AL, Moore EE, Biffl WL, Franciose RJ, Johnson JL, Burch $J M$. Avoidance of abdominal compartment syndrome in damage-control laparotomy after trauma. Arch Surg. 2001;136:676-81.

17. Sharp KW, Locicero RJ. Abdominal packing for surgically uncontrollable hemorrhage. Ann Surg. 1992;215:464-74.

18. Godat L, Kobayashi L, Costantini T, Coimbra R. Abdominal damage control surgery and reconstruction: world society of emergency surgery position paper. World J Emerg Surg. 2013;8:53.

19. Wabiel $B H$, Rotondo MF. Damage control surgery: it's evolution over the last 20 years. Rev Col Bras. 2012;39(4):314-21.

20. Bjorck M, Bruhin A, Cheatham M, Hinck D, Kaplan M, Manca G, Wild T, Windsor A. Classification - Important step to improve management of patients with an open abdomen. World J Surg. 2009;33(6):1154-7. 
21. Bjarnason T, Montgomery A, Acosta S, Petersson U. Evaluation of the open abdomen classification system: a validity and reliability analysis. World J Surg. 2014;38(12):3112-24.

22. Rausei S, Dionigi G, Rovera F, Boni L, Dionigi R. Surgical classification of open abdomen: Which clinical implications? World J Surg. 2010;34(3):599-600.

23. Karmali S, Evans D, Laupland K, Findlay C, Ball CG, Bergeron E, Stewart TC, Parry N, Khetarpal S, Kirkpatrick AW. To close or not to close, that is one of the questions? Perceptions of Trauma Association of Canada surgical members on the management of the open abdomen. J Trauma. 2006;60(2): 287-93.

24. Dubose JJ, Scalea TM, Holcomb JB, Shrestha B, Okoye O, Inaba K, Bee TK, Fabian TC, Whelan J, Ivatury RR, AAST Open Abdomen Study Group. Open abdominal management after damage-control laparotomy for trauma: a prospective observational American Association for the Surgery of Trauma multicenter study. J Trauma Acute Care Surg. 2013;74(1):113-20. discussion 1120-1122.

25. Atena JJ, Gans SL, Boermeester MA. Systematic review and meta-analysis of the open abdomen and temporary abdominal closure techniques in non-trauma patients. World I Surg. 2015;39(4):912-25.

26. Schmelzle M, Alldinger I, Matthaei H, Aydin F, Wallert I, Eisenberger CF, Schulte AM, Esch J 2nd, Dizdar L, Topp SA, Yang Q, Knoefel WT. Long-term vacuum-assisted closure in open abdomen due to secondary peritonitis: a retrospective evaluation of a selected group of patients. Dig Surg. 2010; 27(4):272-8.

27. Khan A, Hsee L, Mathur S, Civil I. Damage-control laparotomy in nontrauma patients: review of indications and outcomes. J Trauma Acute Care Surg. 2013;75(3):365-8

28. Chiara O, Cimbanassi S, Biffl W, Leppaniemi A, Henry S, Scalea TM, Catena F, Ansaloni L, Chieregato A, De Blasio E, Gambale G, Gordini G, Nardi G, Paldalino P, Gossetti F, Dionigi P, Noschese G, Tugnoli G, Ribaldi S, Sgardello S, Magnone S, Rausei S, Mariani A, Mengoli F, Di Silverio S, Castriconi M, Coccolini F, Negreanu J, Razzi S, Coniglio C, Morelli F, Buonanno M, Lippi M, Trotta L, Volpi A, Fattori L, Zago M, De Rai P, Sammartano F, Manfredi R, Cingolani E. International consensus conference on open abdomen in trauma. J Trauma Acute Care Surg. 2016;80(1):173-83.

\section{Submit your next manuscript to BioMed Central and we will help you at every step:}

- We accept pre-submission inquiries

- Our selector tool helps you to find the most relevant journal

- We provide round the clock customer support

- Convenient online submission

- Thorough peer review

- Inclusion in PubMed and all major indexing services

- Maximum visibility for your research

Submit your manuscript at www.biomedcentral.com/submit

C Biomed Central 